Article

\title{
Study on a Novel Recyclable Anticorrosion Gel Coating Based on Ethyl Cellulose and Thermoplastic Polyurethane
}

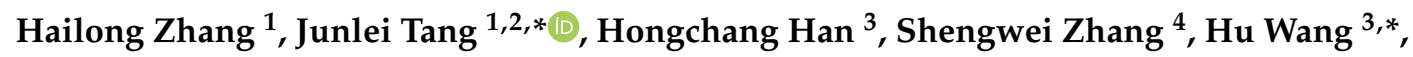 \\ Yingying Wang ${ }^{1}$, Tian $\mathrm{Li}^{4}$ and Bing Lin ${ }^{1}$ \\ 1 School of Chemistry and Chemical Engineering, Southwest Petroleum University, Chengdu 610500, China; \\ hailong0902@126.com (H.Z.); yingyingwanglyon@126.com (Y.W.); h1900@foxmail.com (B.L.) \\ 2 State Key Laboratory of Oil and Gas Reservior Geology and Exploitation, Southwest Petroleum University, \\ Chengdu 610500, China \\ 3 School of Materials Science and Engineering, Southwest Petroleum University, Chengdu 610500, China; \\ hongchang_han@163.com \\ 4 AECC Chengdu Engine Co., Ltd., Chengdu 610500, China; zswabc1111@163.com (S.Z.); \\ dongwu_13@163.com (T.L.) \\ * Correspondence: tangjunlei@126.com (J.T.); senty78@126.com (H.W.); Tel./Fax: + 86-028-8303-7323 (J.T.)
}

Received: 4 September 2019; Accepted: 24 September 2019; Published: 27 September 2019

\begin{abstract}
In this paper, ethyl cellulose, thermoplastic polyurethane, and mineral oil were used as the main raw materials to synthesize a recyclable thermoplastic gel for anticorrosion coatings by a hot melt method. In addition, the effect of thermoplastic polyurethane on the properties of the coating was discussed. The structure and corrosion protection properties of the coating were characterized and analyzed by a scanning electron microscope, transmission electron microscope, $\mathrm{X}$-ray diffraction, infrared spectroscopy, dynamic mechanical analysis, salt spray test, and electrochemical measurements. The results show that the ethyl cellulose and oil in the coating can form a stable organic-gel structure by hydrogen bonding, and the mineral oil and castor oil are uniformly dispersed in the coating. The surface of the coating does not change after $3000 \mathrm{~h}$ of a salt spray test. During the repeated hot melting spraying and immersion in $3.5 \mathrm{wt} . \% \mathrm{NaCl}$ solution for five times, the electrochemical impedance modulus of the coating was always above $10^{9} \Omega \cdot \mathrm{cm}^{2}$, the water absorption rate was always less than $1.5 \mathrm{wt} . \%$, and the mechanical properties of the coating did not decrease. This novel coating could be used for the corrosion protection of flange and valve connections in pipeline and bolting connections in different industries. The disassembly and assembly operation of these connection structures during the regular maintenance will destroy the ordinary anticorrosion coating, and the irregular geometric shape of such places also make difficulties for the preparation of ordinary coatings onsite.
\end{abstract}

Keywords: thermoplastic; ethyl cellulose; anticorrosion coating; recyclable gel; corrosion resistance

\section{Introduction}

Metals are prone to corrosion in the marine environment. In particular, the profiled structure with gaps and connection structures are the most susceptible to localized corrosion such as flanges, valves, welds, and bolts. Therefore, these parts have higher requirements for corrosion protection. The heavy-duty anticorrosion coatings are usually used to protect metallic constructions in marine corrosion [1-4]. However, for the mentioned particular structures, the good shielding property of anticorrosion coating not only depends on the nature of coating material but also requires high thickness and good elasticity of coating to cover the crevice and to withstand the structural deformation [5-8]. The recycling property of coating is desired because the disassembly and assembly operation of these 
connection structures during the regular maintenance will destroy the ordinary anticorrosion coating. In addition, it is beneficial for environmental protection.

At present, most of the heavy-duty anticorrosive coatings are solvent-based crosslinking curing resins, such as epoxy resin [5,6], polyurethane [9], and acrylic resin [8,10]. In the process of connection structures installation and later maintenance, the disassembly and assembly operation are easy to cause damage to these coatings and reduce the protection performance of the coating. The peeled coating cannot be reused and needs to be resprayed, which not only causes environmental pollution but also wastes earth resources. Moreover, it is difficult to clean the complex surface of the connections effectively on site, which brings great challenges and difficulties for respraying the new coatings with a desired quality. Therefore, the solvent-based crosslinking curing coating is not good for these specific places.

Compared with crosslinking curing resins, thermoplastic resins have the characteristics of low energy consumption, solvent-free, and recyclable, and it is often used in the preparation of powder spraying coatings, such as polyolefine [11,12], polyamide [13,14], polyester $[13,15]$, and polycarbonate $[16,17]$. However, these typical thermoplastic resins as mentioned previously have the characteristics of high hot melting temperature, poor flowability, high requirement for surface cleanliness of materials, complex spraying equipment, and more. Therefore, they are often used for indoor fabrication of protective coating in different industries [16-19], but not suitable for on-site spraying of coatings.

Ethyl cellulose (EC) is a commonly used cellulose derivative, which has the characteristics of the thermoplastic polymer and can be prepared by etherification of natural cellulose. It has excellent film forming properties, chemical resistance, and degradability [20]. It is often used as a coating additive [21-23] and medical film [24-26]. It is reported that ethyl cellulose has good compatibility with mineral oil and castor oil to form a stable oil gel, and the mechanical strength of the oil gel can be adjusted by changing the proportion of oil components [23]. Juan Yu et al. [27] prepared a series of thermoplastic elastomers with different strength and toughness from ethyl cellulose, fatty acids, and furfural. Abbaspoor et al. [28] prepared an ethyl cellulose capsule containing linseed oil by an emulsion-solvent evaporation method, and dispersed the capsule in the polyurethane coating to improve the corrosion resistance of the coating. According to previous studies, it is possible to develop a thermoplastic gel material with good chemical stability and good elasticity based on the advantages of ethyl cellulose, oil, and elastomer components.

Therefore, a recyclable anticorrosion gel coating composed of ethyl cellulose, thermoplastic polyurethane (TPU), and mineral oil was developed on carbon steel substrate in our study. The features and properties of the coating were investigated by a scanning electron microscope, a transmission electron microscope, $\mathrm{X}$-ray diffraction, infrared spectroscopy, dynamic mechanical analysis, a salt spray test, and electrochemical measurements. This novel environmentally-friendly coating could be used for the corrosion protection of flange and valve connections in pipeline, and the bolting connections in different industrial environments, especially in the marine environment.

\section{Materials and Methods}

\subsection{Materials}

Mineral oil and castor oil were supplied by Kelong Chemical Reagent Company (Chengdu, China). The mineral oil was selected of viscosity about $12 \mathrm{cSt}$ at room temperature and the boiling point is $255{ }^{\circ} \mathrm{C}$. Castor oil contains $80 \%$ ricinoleic acid and $10 \%$ oleic acid with a boiling point of $330^{\circ} \mathrm{C}$. Thermoplastic polyurethane was produced by Taiwan sheen soon Co., Ltd.(Taiwan, China). Ethyl cellulose and $\mathrm{TiO}_{2}$ were purchased from Shanghai Aladdin Biochemical Technology Co., Ltd (Shanghai, China).

Carbon steel Q235 with the composition of 0.2 wt.\% C, 0.35 wt.\% Si, 1.40 wt.\% Mn, 0.045 wt.\% P, $0.05 \mathrm{wt} . \% \mathrm{~S}$, and balance Fe was used in this study. It was cut into sheets with different scales for different experimental requirements, which will be introduced in the relative experimental part, respectively. 


\subsection{Preparation of Gel and Coating}

The gel material was prepared by the melt blending method. A total of $6.0 \mathrm{~g}$ of EC, $4.0 \mathrm{~g}$ of mineral oil, $2.0 \mathrm{~g}$ of castor oil, and $0.12 \mathrm{~g}$ of $\mathrm{TiO}_{2}$ with a particle size of about $100 \mathrm{~nm}$ were mixed and heated with stirring at $180^{\circ} \mathrm{C}$. When the raw material was completely melted and mixed uniformly, it was cooled to obtain a C-EC gel. Similarly, $6.0 \mathrm{~g}$ of ethyl cellulose, $4.0 \mathrm{~g}$ of mineral oil, $2.0 \mathrm{~g}$ of castor oil, $2.0 \mathrm{~g}$ of TPU, and $0.14 \mathrm{~g}$ of $\mathrm{TiO}_{2}$ were mixed and heated with stirring at $180^{\circ} \mathrm{C}$. When the raw material was completely melted and mixed uniformly, it was cooled to obtain a C-EC/TPU gel. Anatase- $\mathrm{TiO}_{2}$ was added to the coating to absorb ultraviolet light to improve the aging resistance of the coating.

The coatings about $2 \mathrm{~mm}$ thick with a thickness deviation of about $0.1 \mathrm{~mm}$ were prepared by hot melt spraying gel materials using a hot glue gun (HB700KD, Buhnen, Germany) on a carbon steel substrate with different scales.

\subsection{Material Characterization and Property Measurement}

The samples were mounted on SEM stubs with double-sided adhesive tape, and then coated with gold. A SEM (EVOMA15, ZEISS, Aalen, Germany) was used to observe the morphologies of the surface and cross sections of the coating at an accelerating voltage of $20 \mathrm{kV}$.

The structure of the sample was observed using a transmission electron microscope (TEM) (Tecnai G2F20S-TWIN, FeieiECTRONOptics, OR, USA) at an acceleration voltage of $200 \mathrm{kV}$. The ultra-thin cryo-section of samples were prepared for testing.

Fourier transform infrared spectra (FT-IR) of samples were recorded on a Nicolet 740 infrared spectrophotometer equipped. The spectra were recorded by averaging 32 scans at a resolution of $2 \mathrm{~cm}^{-1}$ from $4000 \mathrm{~cm}^{-1}$ to $500 \mathrm{~cm}^{-1}$.

The possible crystal structures of the samples were analyzed by X-ray diffraction. It was recorded by X-ray Diffraction (XRD) (X'Pert PRO, PANalaytical) with $\mathrm{Cu}$ Ka radiation, and the scanning angle was from $10^{\circ}$ to $90^{\circ}$.

The dynamic mechanical analysis (DMA) of the samples were tested by DMAQ800. The sample was scanned at a temperature of $3{ }^{\circ} \mathrm{C} /$ min under a dry nitrogen blanket from $-50{ }^{\circ} \mathrm{C}$ to $100{ }^{\circ} \mathrm{C}$. Tan $\theta$ and storage modulus were collected at a frequency of $1 \mathrm{~Hz}$.

The corrosion resistance of the samples was characterized by a neutral salt spray test in a $35^{\circ} \mathrm{C}$, and a $5 \mathrm{wt} . \% \mathrm{NaCl}$ solution environment, according to ASTM B117-90. The sample size was $40 \mathrm{~mm} \times$ $80 \mathrm{~mm} \times 2 \mathrm{~mm}$. The corrosion resistance of the sample was evaluated by observing the surface change of the sample during the 3000-h test.

The UV aging test of the coating was performed using Q-Lab's Quv/Spray accelerated aging equipment. The ASTM standard G154-Cycle1 was used. The coated samples with a size of $7.5 \mathrm{~cm} \times$ $15 \mathrm{~cm}$ were alternately exposed to UV radiation at $60^{\circ} \mathrm{C}$ for $8 \mathrm{~h}$ in a cyclic manner, and then condensed in water at $50{ }^{\circ} \mathrm{C}$ for $4 \mathrm{~h}$. The irradiance of the ultraviolet light was $0.89 \mathrm{~W} / \mathrm{m}^{2}$. The distance between the center of the lap and the sample is about $50 \mathrm{~mm}$.

Electrochemical impedance spectroscopy (EIS) was measured using a three-electrode system by the Corr-Test electrochemical workstation. Platinum was used as the auxiliary electrode. The coated steel sheet was used as the working electrode. The sample size was $70 \mathrm{~mm} \times 70 \mathrm{~mm} \times 2 \mathrm{~mm}$. The saturated calomel electrode (SCE) was used as the reference electrode. The EIS experiment was tested after the stabilization of open circuit potential. The amplitude of disturbance voltage was $20 \mathrm{mV}$ and the frequency ranged from $100 \mathrm{kHz}$ to $0.01 \mathrm{~Hz}$. All electrochemical measurements were performed in $3.5 \mathrm{wt} . \% \mathrm{NaCl}$ solution at room temperature.

\subsection{Cyclic Spraying and Performance Test of Coating}

The schematic diagram of the fifth melting cycle test of C-EC/TPU coating is shown in Figure 1. The sample size is $70 \mathrm{~mm} \times 70 \mathrm{~mm} \times 2 \mathrm{~mm}$. The hot melt spraying of coating at $180^{\circ} \mathrm{C}$ is shown in Figure 2. A total of nine parallel samples were used for the cycle test, including three of which were 
tested for EIS, three were tested for tensile strength testing, and three were tested for water absorption testing. First, the tensile strength and the weight of the coating were measured. Then, the coating was immersed in a $3.5 \mathrm{wt} . \% \mathrm{NaCl}$ solution and the electrochemical AC impedance was tested at the beginning of the immersion, and the electrochemical AC impedance of the coating was again tested after 30 days of immersion. For one parallel sample, the surface of the coating was dried first. Then, the coating was peeled off from the surface of the substrate, and the weight of the coating was weighed to calculate the water absorption after 30 days of immersion. For another eight parallel samples, the tensile strength of peeled off coating was measured after 30 days of immersion. Then, each coating sample was melted and resprayed on the surface of the substrate again. Five cycles of testing were performed in sequence.

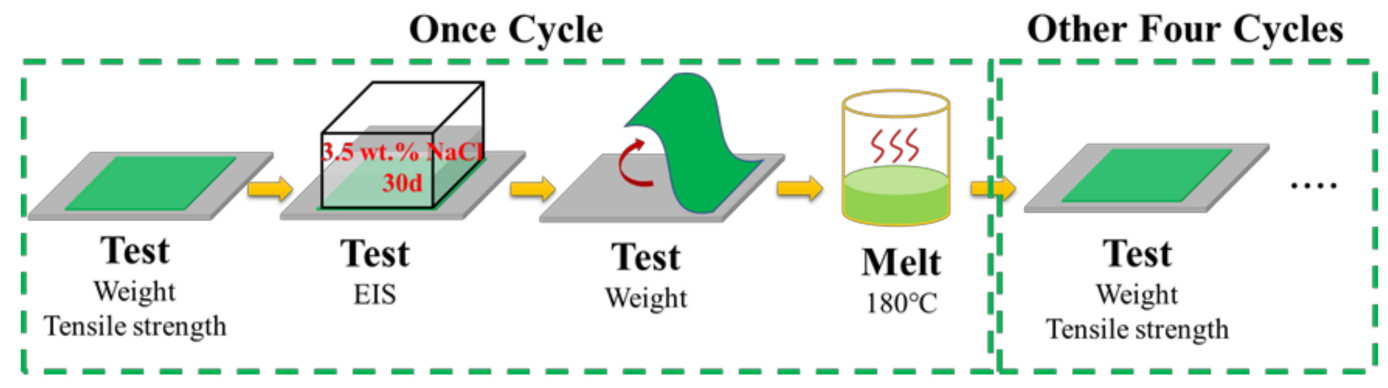

Figure 1. Schematic diagram of the cycle performance of C-EC/TPU coating.
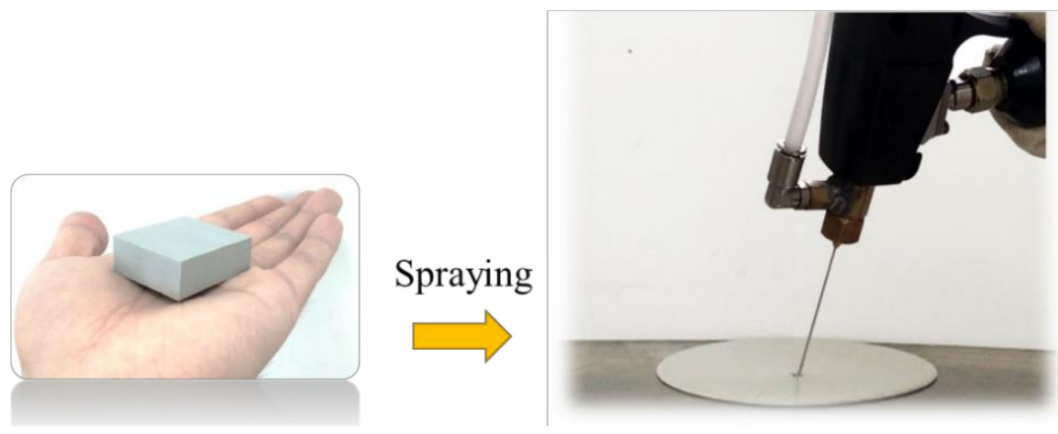

Figure 2. The hot melt-spraying of C-EC/TPU coating at $180^{\circ} \mathrm{C}$.

\section{Results and Discussion}

\subsection{FT-IR Spectra}

Figure 3 shows the infrared spectra spectrum of C-EC, C-EC/TPU, EC, and TPU. The peak at $3470 \mathrm{~cm}^{-1}$ was attributed to the vibration of the $-\mathrm{OH}$ group [29]. As shown in Figure $4 \mathrm{~g}$, EC is the product of cellulose after etherification reaction, but there are still many $-\mathrm{OH}$ groups on the EC molecule. In addition, the castor oil molecule contains $-\mathrm{COOH},-\mathrm{C}=\mathrm{C}-$ and $-\mathrm{OH}$ groups. The peaks at $1640 \mathrm{~cm}^{-1}$ and $1376 \mathrm{~cm}^{-1}$ were attributed to the vibration of $-\mathrm{COO}$ and $-\mathrm{C}=\mathrm{C}-$ on the castor oil molecule $[30,31]$, respectively. Compared with the EC spectrum, the peak at $1100 \mathrm{~cm}^{-1}$ in the C-EC spectrum was attributed to the vibration of the $-\mathrm{C}-\mathrm{O}-\mathrm{C}$ - group on the EC molecule. Compared with the EC and TPU spectrum, the peak at $1637 \mathrm{~cm}^{-1}$ in the C-EC/TPU spectrum was attributed to the vibration of the $\mathrm{R}-\mathrm{NH}_{2}$ group on the TPU molecule. The peaks at $1070 \mathrm{~cm}^{-1}$ were attributed to the superposition vibration of the $\mathrm{C}-\mathrm{N}$ group on the TPU molecule and the $-\mathrm{C}-\mathrm{O}-\mathrm{C}-$ on the EC molecule [32]. The peaks at $1747 \mathrm{~cm}^{-1}$ in the C-EC and C-EC/TPU spectra were attributed to the vibration of the ester $\mathrm{C}=\mathrm{O}$ group, which may be due to the reaction of $-\mathrm{COOH}$ with $-\mathrm{OH}$. As indicated from the IR results, no clear chemical reactions occurred between the functional groups of different molecules in two coatings except a small esterification reaction. 


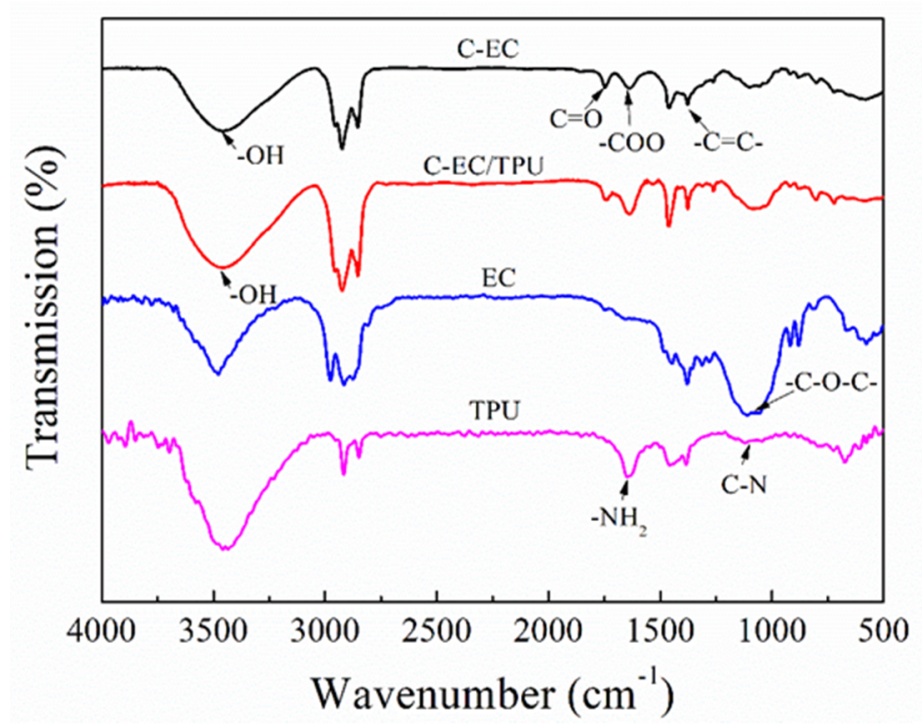

Figure 3. FT-IR spectra of C-EC and C-EC/TPU.

\subsection{SEM Observation}

Figure $4 \mathrm{a}$, d show the surface and cross-sectional microscopic morphology of C-EC and C-EC/TPU coatings. Figure 4e,f were the "groove" width profiles in Figure $4 b$,d, respectively. Figure $4 a, c$ show that the C-EC and C-EC/TPU surfaces were smooth with no clear defects. The cross-section of the C-EC coating had a number of "groove" structures with a scale of 3-10 $\mu \mathrm{m}$ from Figure $4 \mathrm{~b}$,e. Figure $4 \mathrm{~d}$ shows the C-EC/TPU cross-sectional microstructure. The C-EC/TPU cross-section was flatter and denser than the C-EC cross-section. The "groove" scale was concentrated at 1-2 $\mu \mathrm{m}$.

Although there is no clear chemical reaction between the main compositions of coatings from FT-IR analysis. EC and castor oil molecules had many unsubstituted hydroxyl and carboxyl groups. A strong hydrogen bond can be formed between these hydroxyl groups and carboxyl groups to form a cage construction $[23,33]$. The "sponge" morphology was observed in Figure $4 b$,d. Then, the mineral oil was filled in the cage construction. For the C-EC/TPU gel coating, the TPU molecule contains an amino group, which could form a hydrogen bond with the hydroxyl group and the carboxyl group as well. A crosslinking structure was formed by the bonding of EC, castor oil, and TPU molecules. The crosslinking and interpenetration networks made the internal structure of the cage construction more compact [34] in C-EC/TPU gel coating, as confirmed in Figure 4d,g. It indicated that TPU have a strengthening effect on gel coating.

\subsection{TEM Observation}

Figure 5 shows TEM images and energy dispersive X-ray spectroscopy (EDX) spectrum of C-EC and C-EC/TPU. The $\mathrm{TiO}_{2}$ particles had a diameter of about $100 \mathrm{~nm}$, and its edge was relatively smooth with the polymer. Anatase- $\mathrm{TiO}_{2}$ was added to the coating to absorb ultraviolet light to improve the aging resistance of the coating. It indicated that $\mathrm{TiO}_{2}$ had good compatibilities with the two coatings. No impurities were observed in the images, which indicates that the gel coating formed a homogeneous micro-structure on a nanoscale. 

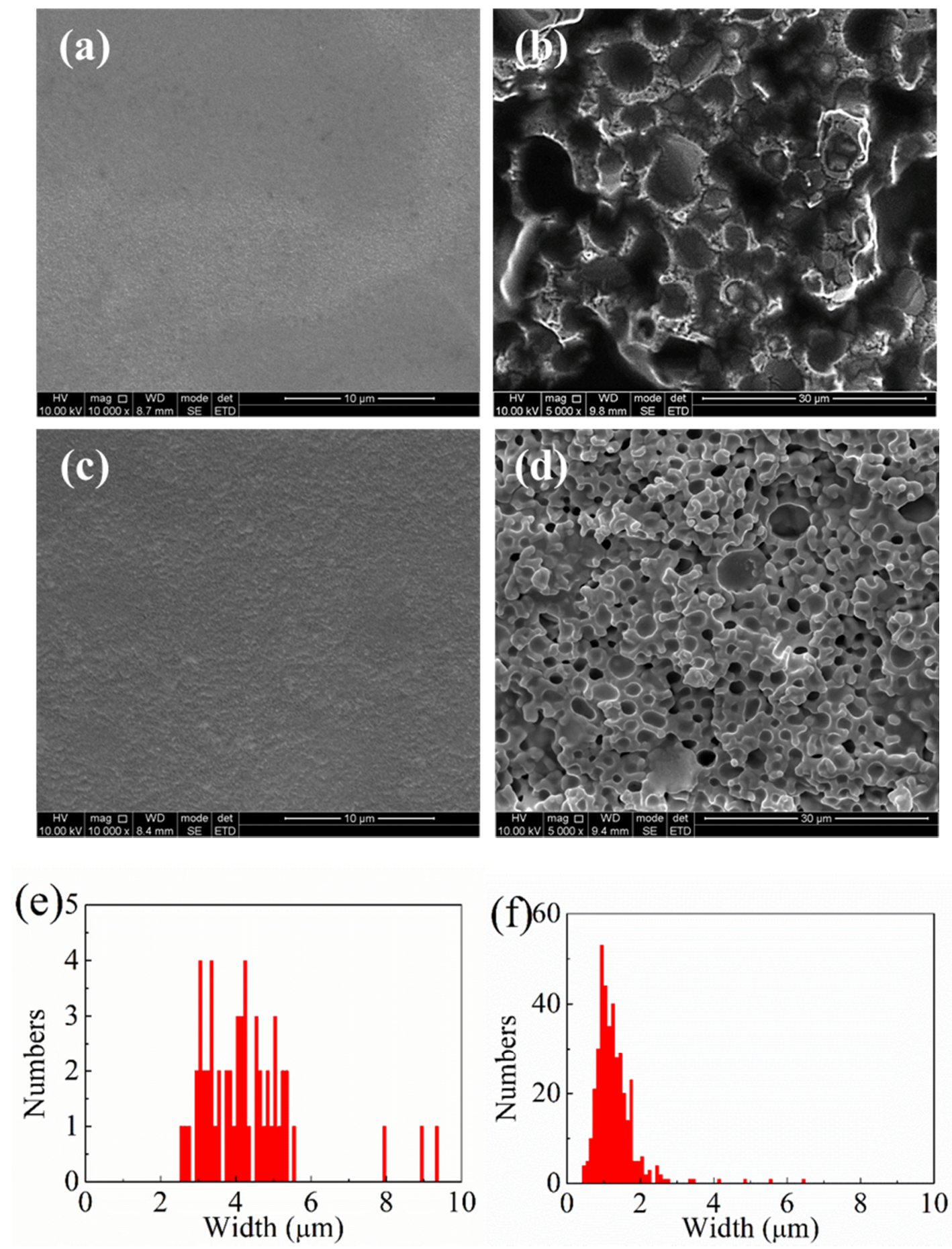

Figure 4. Cont. 
(g)

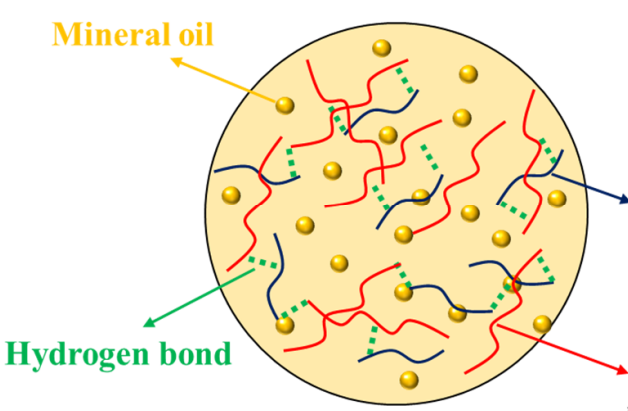

C-EC $-\prod^{0} \int^{0}$

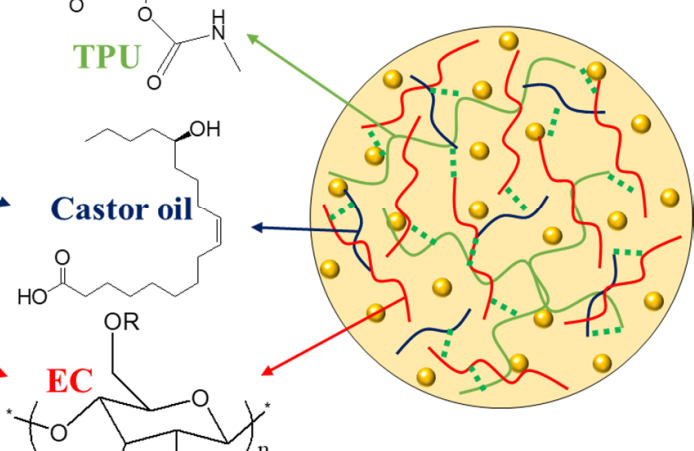

C-EC/TPU

Figure 4. SEM images of (a) the surface of C-EC coating, (b) the cross-section of C-EC coating, (c) the surface of C-EC/TPU coating, (d) the cross-section of C-EC/TPU coating, (e) the "groove" scale profiles in Figure 4b, (f) the "groove" scale profiles in Figure 4d, (g) The C-EC and C-EC/TPU materials model the diagram.
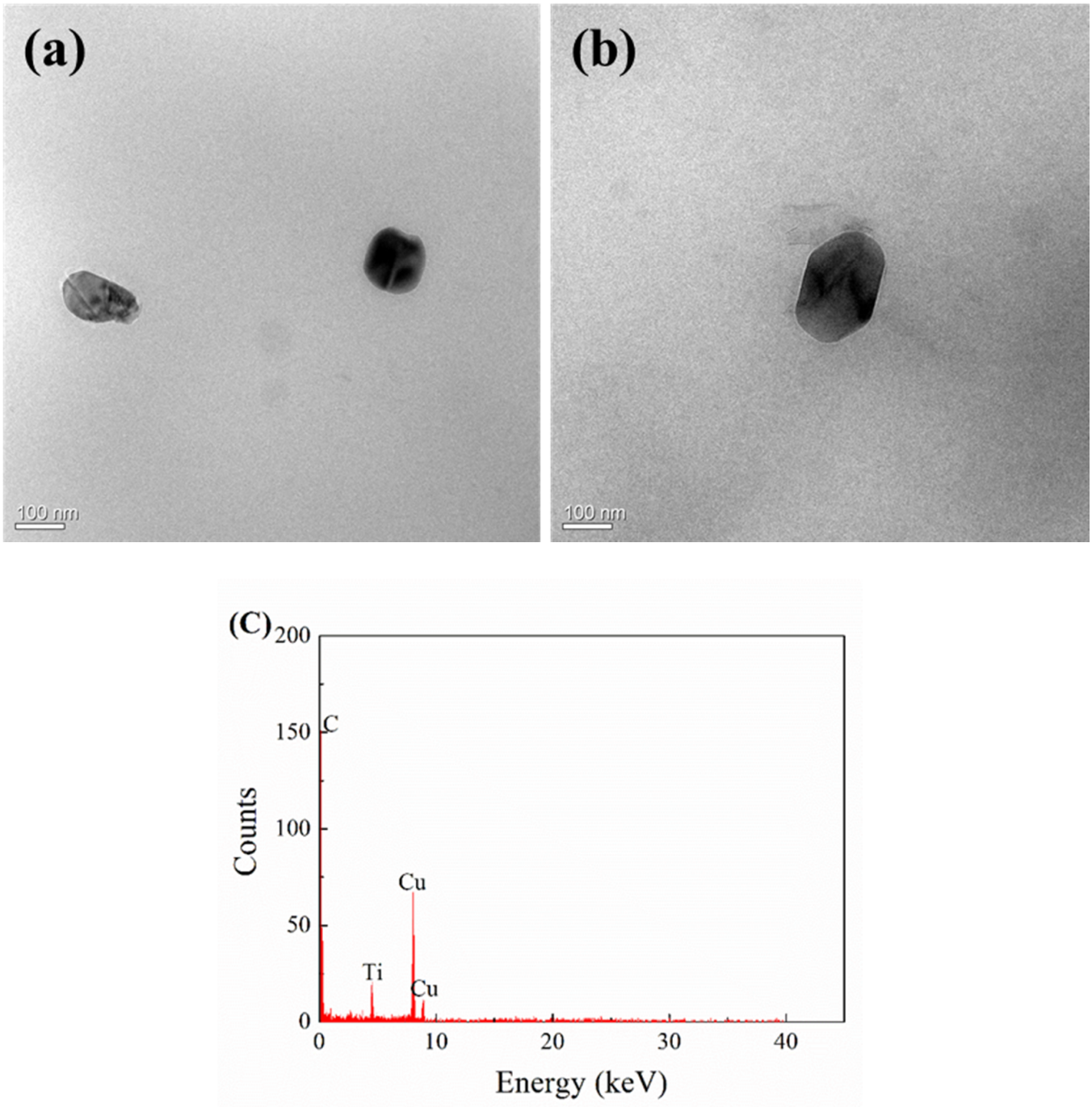

Figure 5. TEM micrographs of the (a) C-EC, (b) C-EC/TPU, and (c) EDX spectrum. 


\subsection{XRD Analysis}

Figure 6 shows the XRD pattern of the C-EC and C-EC/TPU. It can be seen that two coatings have almost the same patterns, which displayed typical peaks of semi-crystalline, since both patterns have an extremely broadened peak at $20^{\circ}$. It had been reported that the pure EC had a broad diffraction peak at around $2 \theta$ of $20^{\circ}$ [35]. $\mathrm{TiO}_{2}$ peaks could be found in two samples at $2 \theta=25.7^{\circ}, 38.1^{\circ}, 48.4^{\circ}, 54.1^{\circ}$, $55.4^{\circ}, 63^{\circ}, 69^{\circ}, 70.6^{\circ}, 75.3^{\circ}$ and $83^{\circ}$ [36]. Furthermore, peaks at $2 \theta=22^{\circ}$ and $24^{\circ}$ could be attributed to methyl stearate [37], which is in accordance with the $\mathrm{C}=\mathrm{O}$ group identified in the IR spectrum at the peak $1747 \mathrm{~cm}^{-1}$.

The XRD spectra indicated that the C-EC and C-EC/TPU coatings have a similar crystalline structure in the polymer phase. Because castor oil contains more ricinoleic acid [38], the carboxyl group in ricinoleic acid could be esterified by reacting with the hydroxyl group to form a crystalline stearate.

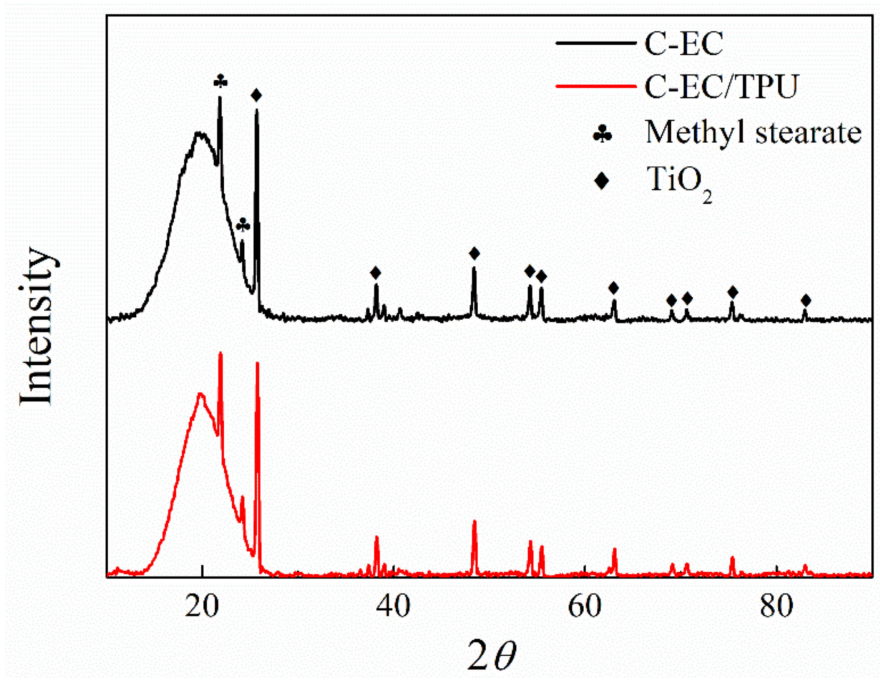

Figure 6. X-ray diffraction pattern of the C-EC and C-EC/TPU.

\subsection{DMA Analysis}

Figure 7 shows the DMA spectra of C-EC and C-EC/TPU. It can be seen from Figure 7a that the storage modulus of C-EC decreased rapidly from 175 to $75 \mathrm{MPa}$ at $-44^{\circ} \mathrm{C}$, with a decrease of about $57 \%$. It increased to 100 from $75 \mathrm{MPa}$ first and then dropped rapidly with the increase of temperature. When the temperature rises to $70{ }^{\circ} \mathrm{C}$, the storage modulus of C-EC was close to $0 \mathrm{MPa}$. The storage modulus of C-EC/TPU was higher than $230 \mathrm{MPa}$ when the temperature was lower than $10^{\circ} \mathrm{C}$. Then, it decreased rapidly and approached $0 \mathrm{MPa}$ at $90^{\circ} \mathrm{C}$. As can be seen from Figure $7 \mathrm{~b}$, the $\tan \theta$ of $\mathrm{C}$-EC reaches a maximum at $58^{\circ} \mathrm{C}$, and the $\tan \theta$ of C-EC/TPU reached a maximum at $83^{\circ} \mathrm{C}$.

There were many small oil molecules in the two coatings. The oil molecules may flow through grooves when the temperature rises. The intermolecular force gradually decreases with the increase of temperature. The increase of molecular motion will result in the decrease of the storage modulus. As discussed previously, the EC and castor oil molecules formed hydrogen bonds with each other because of hydroxyl and carboxyl groups. As the temperature increased, the hydrogen bond force decreased, which leads to the storage modulus of the material decreasing gradually [23]. Compared with the C-EC, the C-EC/TPU contains the amino group, and the amino group also has the hydrogen bond with the hydroxyl group and the carboxyl group. Furthermore, the energy needed to break the binding was increased. Therefore, the storage modulus of C-EC/TPU was higher than that of C-EC. After the addition of TPU, the loss factor peak shifted to a high temperature because the TPU chain length is longer than other materials, and the intermolecular force is enhanced by the action of hydrogen bonding, which reduced the molecular mobility $[39,40]$. Consequently, the mechanical property and thermal stability of C-EC/TPU is better due to the strengthening effect of TPU. 

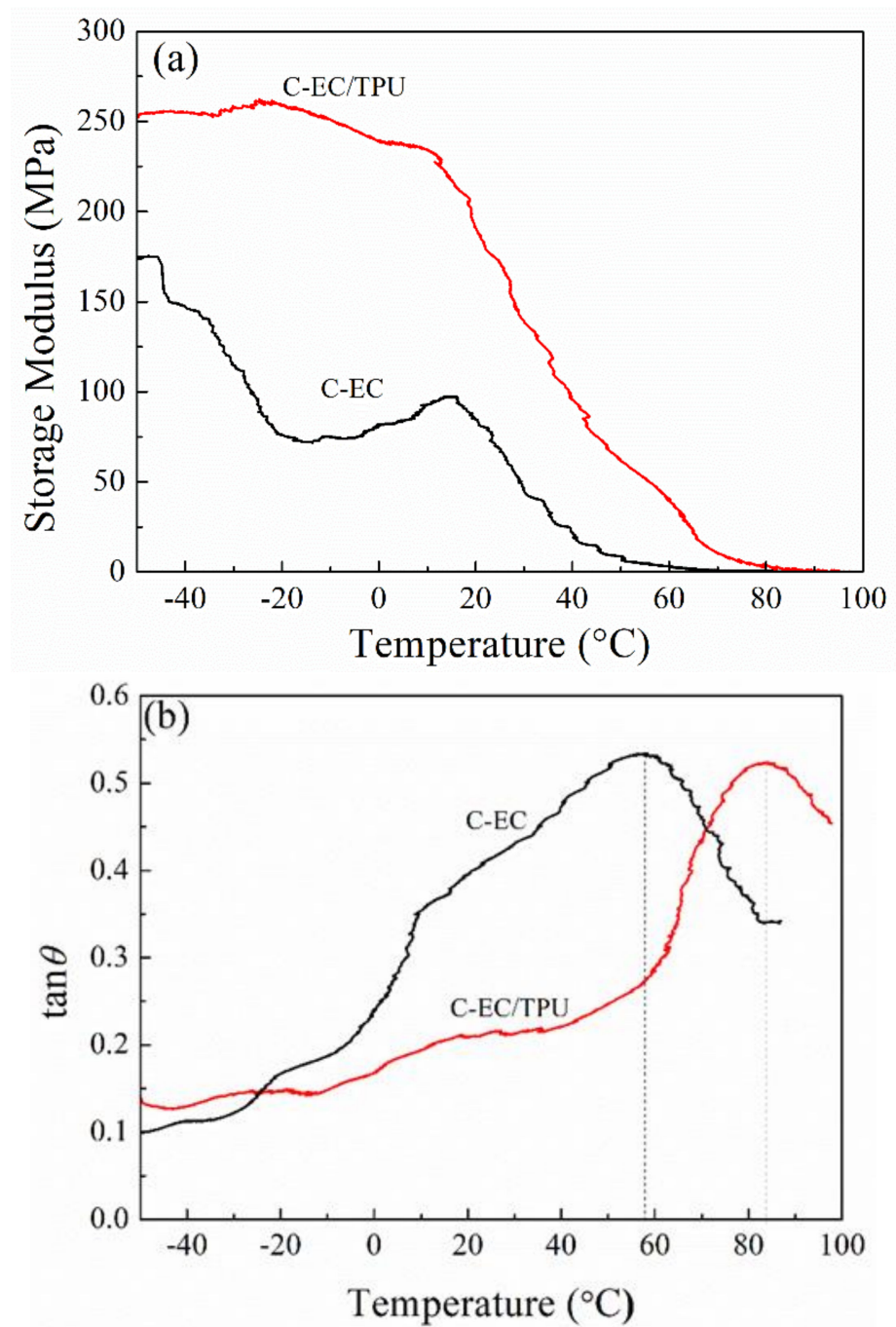

Figure 7. The relationship between (a) storage modulus and (b) loss factor $(\tan \theta)$ and temperature of C-EC and C-EC/TPU coatings.

\subsection{Salt Spray Test and Ultraviolet Aging Test}

Figure 8 shows the surface morphology of C-EC and C-EC/TPU coatings during the 3000-h salt spray test. It was found that no clear changes, such as cracking and discoloration, were observed on the surface of the two coatings during the test process. Therefore, the two coatings have passed the $3000 \mathrm{~h}$ of the salt spray test, according to ASTM B117-90 standard, which indicated that the two coatings both have good corrosion resistance. This was attributed to the excellent chemical stability of EC and TPU, and the oily components in the coatings also blocked the penetration of corrosive media.

Figure 9 shows the morphology of the C-EC and C-EC/TPU during the UV aging test. It could be seen that the surface of C-EC showed significant damage after $240 \mathrm{~h}$ of testing, but the surface of C-EC/TPU only slightly yellowed after $400 \mathrm{~h}$ of testing. It can be seen from Section 3.2 that EC and castor oil form a cross-linked interpenetrating network structure through hydrogen bonding in C-EC materials. In addition, EC, castor oil, and TPU worked together to form cross-linking and interpenetrating in $\mathrm{C}-\mathrm{EC} / \mathrm{TPU}$ materials. Since castor oil contains more $-\mathrm{COOH}$ and $-\mathrm{C}=\mathrm{C}-$, these reactive functional groups are easily destroyed by ultraviolet light [41]. Therefore, the skeleton structure of the C-EC material is easily destroyed, whereas the skeleton structure formed by TPU and EC in the C-EC/TPU is relatively stable. Therefore, the C-EC/TPU gel coating has a better corrosion resistant property. 

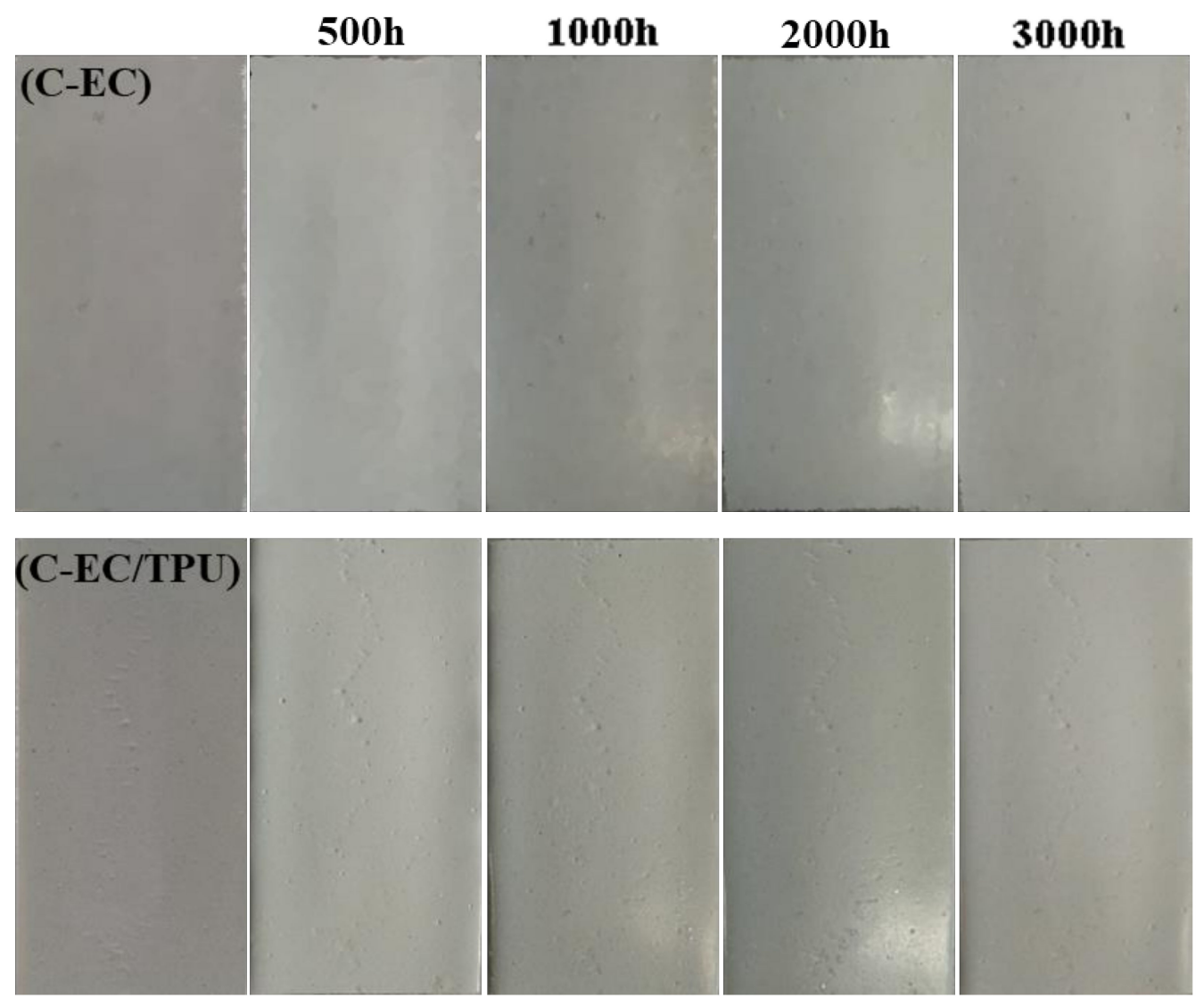

Figure 8. Surface morphology of sample after 500 h, 1000 h, 2000 h, and 3000 h salt spray test.
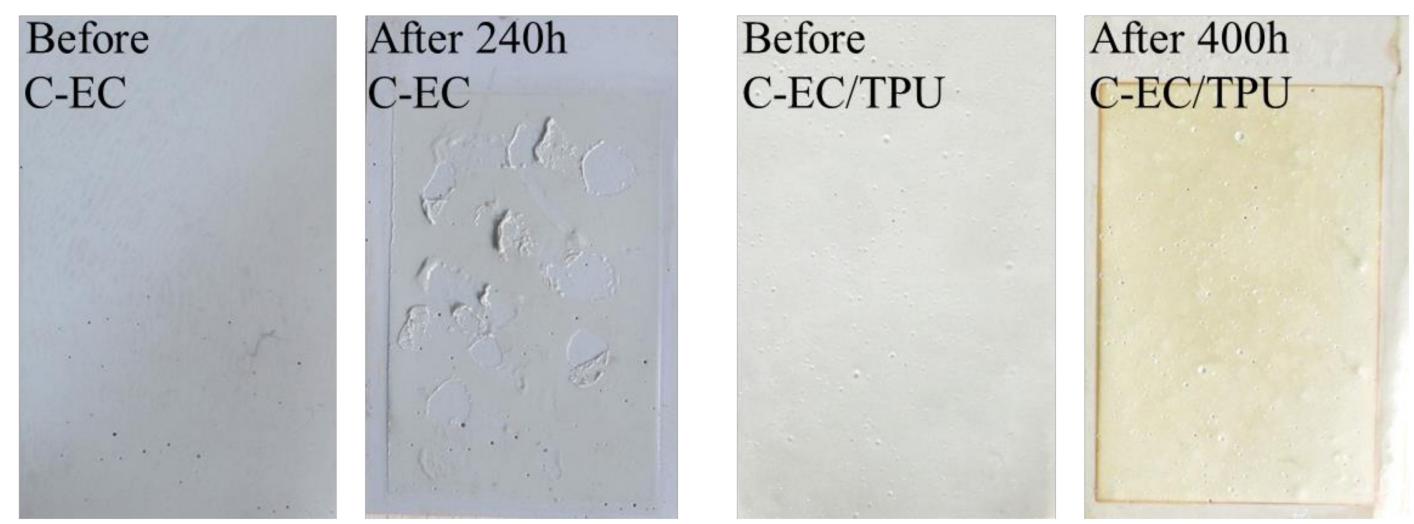

Figure 9. Surface morphology of coating samples before and after UV aging.

\subsection{Cyclic Performance of Coating}

Figure 10 shows the EIS plots of two coatings immersed in a $3.5 \mathrm{wt} . \% \mathrm{NaCl}$ solution for 150 days. Only one semi-arc in the Nyquist diagram at the time of both coatings and the maximum mode value was always more than $10^{9} \Omega \cdot \mathrm{cm}^{2}$ in the Bode diagram, in which the phase angle is very close to $90^{\circ}$ in a wide frequency range as well. Figure 10e shows the change in coating resistance for each coating over 150 days, which is calculated from the EIS spectrum using an equivalent electrical circuit, as shown in Figure 10f. $R_{S}$ is the solution resistance, and $Q$ and $R_{p}$ are the coating capacitance and the coating resistance, respectively [42]. It can be seen from the figure that the $R_{p}$ value has a certain decrease seven days before the start of immersion, and gradually increases during the immersion to 90 days, and finally gradually stabilizes. This may be due to the presence of some surficial graves in the coating that were not completely full filled with oil. In that case, the aqueous solution can quickly seep into 
these graves during the initial immersion time. As the immersion time increased, the oil inside the coating gradually diffused toward the coating surface and some of the permeated aqueous solution was squeezed out. Lastly, the diffusion rate of oil to the surface and the penetration rate of the aqueous solution to the inside reached equilibrium.

(a)

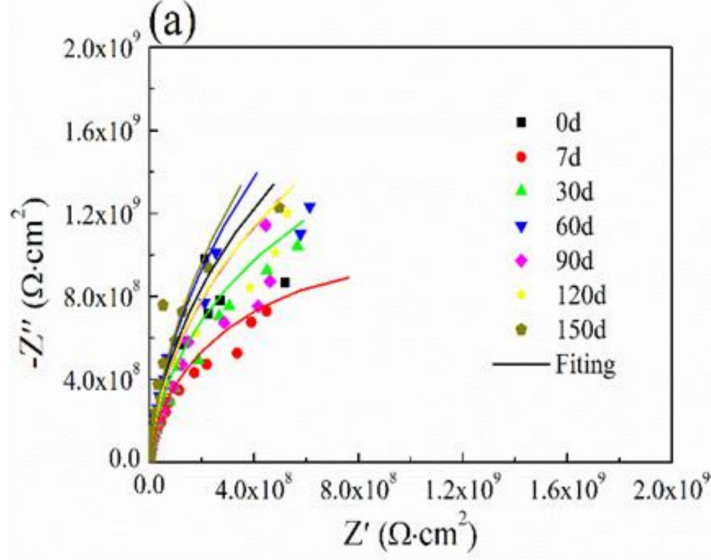

(c)
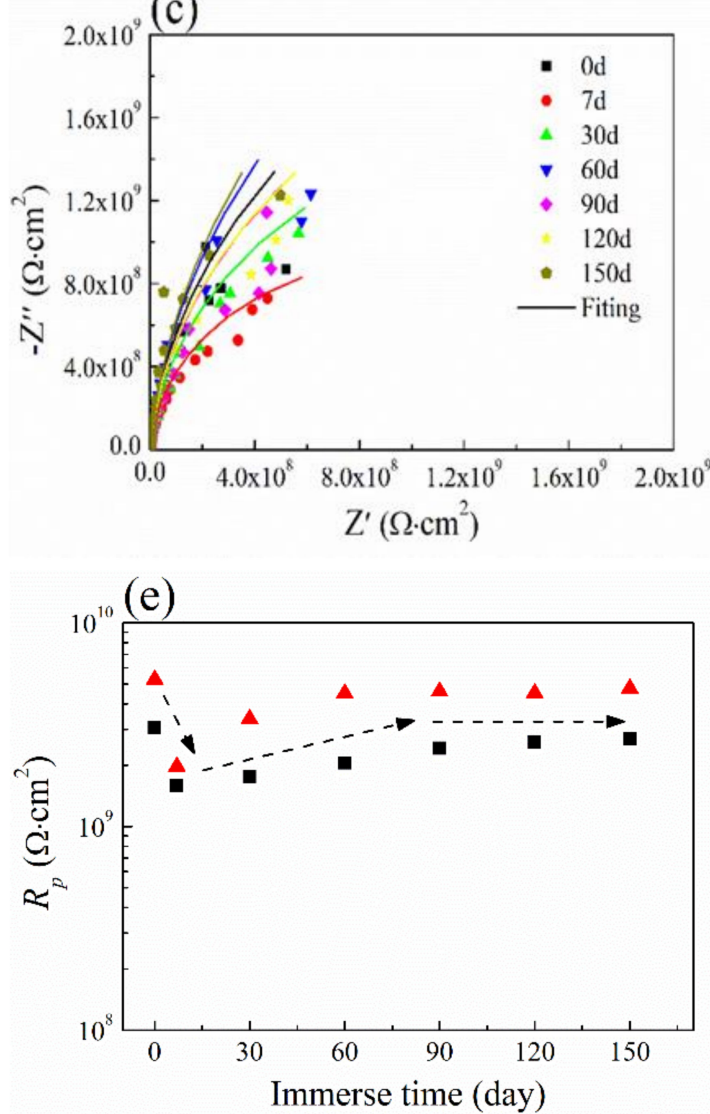

(b)

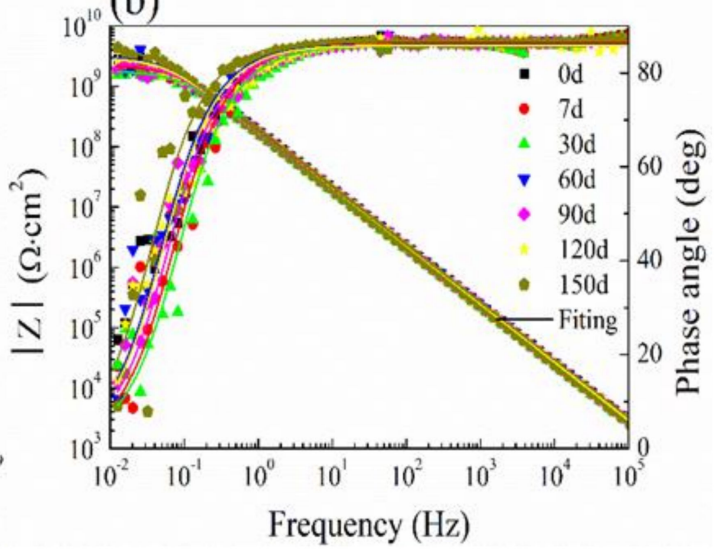

(d)

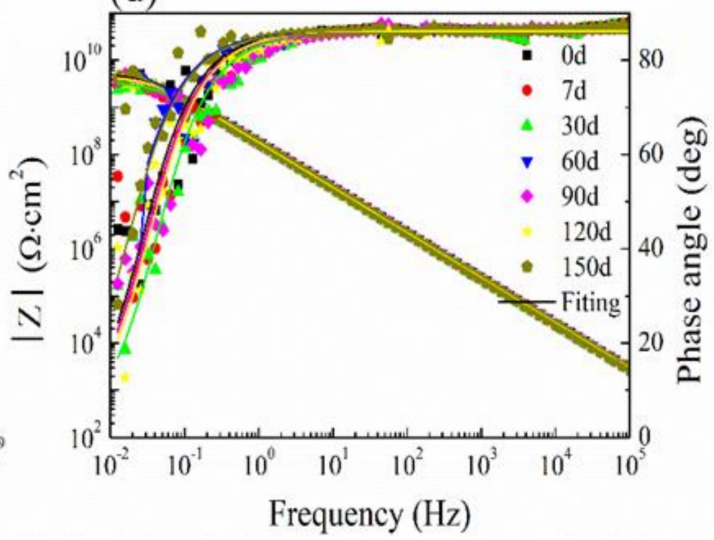

(f)

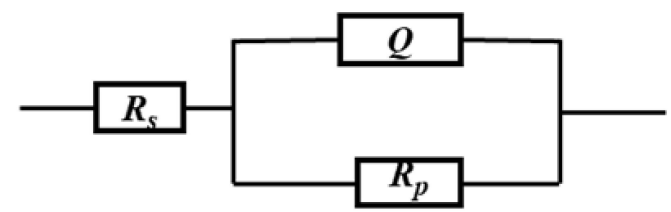

Figure 10. The EIS measurements during 150 days immersion in $3.5 \mathrm{wt} . \% \mathrm{NaCl}$ solution, (a) the Nyquist plot of C-EC gel coating, (b) the Bode plot of C-EC gel coating, (c) the Nyquist plot of C-EC/TPU gel coating, (d) the Bode plot of C-EC/TPU gel coating, (e) the coating resistance change, and (f) the equivalent electrical circuit.

However, the $R_{p}$ values of C-CE/TPU gel coating were always higher than that of C-CE gel coating. The EIS measurement also revealed the C-CE/TPU gel coating had better corrosion resistance. Therefore, the recycling performance was further studied for the C-EC/TPU gel coating. 
Figure 11 shows the electrochemical impedance spectroscopies of C-EC/TPU gel coating during five cycles in $3.5 \mathrm{wt} . \% \mathrm{NaCl}$ solution. When the impedance data before 30 days of immersion of each cycle with the one after was compared, it could be seen that the diameter of the semi-arc decreases in the Nyquist diagram after immersion. This indicates that the water molecules have started to permeate from the coating surface to the inner surface with the extension of immersion time [43,44]. However, there was only one semi-arc in the Nyquist diagram at the time and the maximum mode value was always more than $10^{9} \Omega \cdot \mathrm{cm}^{2}$ in the Bode diagram, in which the phase angle was very close to $90^{\circ}$ in a wide frequency range. It indicated that the corrosive solution had never permeated deep and far away from the coating/carbon steel substrate interface.

In order to further analyze the EIS results, all the electrochemical impedance spectroscopy were fitted with the equivalent circuit diagram model in Figure 10f. The fitting results are shown in Table 1. Figure 12 shows the variation of the $R_{p}$ value and the sample weight change with the number of cycles. It could be observed that the value of $R_{p}$ decreased to a certain extent and the coating weight increased to a certain extent after immersion in each cycle, which indicates the permeation of water molecules into the coating. However, the value of $R_{p}$ was always greater than $10^{9} \Omega \cdot \mathrm{cm}^{2}$ in the process of five cycles, and the weight increase of the coating was less than $1.5 \%$ after immersion at the same time. As shown in Figure 13, the tensile strength of the sample was tested after each melting cycle. It could be seen that the tensile strength fluctuates $1.5 \mathrm{MPa}$ and did not decrease significantly.

Table 1. The electrochemical fitting parameters of EIS of C-EC/TPU coating for five cycles.

\begin{tabular}{cccccc}
\hline \multicolumn{2}{c}{ Test Conditions } & $\boldsymbol{R}_{\boldsymbol{s}}\left(\mathbf{\Omega} \cdot \mathbf{c m}^{\mathbf{2}}\right)$ & $\boldsymbol{Q} \mathbf{( F \cdot \mathbf { c m } ^ { - 2 } )}$ & $\boldsymbol{R}_{\boldsymbol{p}}\left(\mathbf{\Omega} \cdot \mathbf{c m}^{\mathbf{2}}\right)$ & $n$ \\
\hline \multirow{2}{*}{ Before the cycle } & Before immersion & $5.420 \times 10^{-2}$ & $1.3 \times 10^{-9}$ & $6.454 \times 10^{9}$ & 0.9523 \\
& After immersion & $4.01 \times 10^{-3}$ & $1.063 \times 10^{-9}$ & $4.331 \times 10^{9}$ & 0.9495 \\
\hline \multirow{2}{*}{ Cycle once } & Before immersion & $3.805 \times 10^{-4}$ & $1.033 \times 10^{-9}$ & $5.193 \times 10^{9}$ & 0.9517 \\
& After immersion & $1.023 \times 10^{-2}$ & $9.553 \times 10^{-10}$ & $3.357 \times 10^{9}$ & 0.9610 \\
\hline \multirow{2}{*}{ Cycle 2 times } & Before immersion & $2.45 \times 10^{-3}$ & $1.035 \times 10^{-9}$ & $3.402 \times 10^{9}$ & 0.9533 \\
& After immersion & $7.67 \times 10^{-3}$ & $9.929 \times 10^{-10}$ & $1.191 \times 10^{9}$ & 0.9590 \\
\hline \multirow{2}{*}{ Cycle 3 times } & Before immersion & $1.487 \times 10^{-2}$ & $1.023 \times 10^{-9}$ & $1.898 \times 10^{9}$ & 0.9553 \\
& After immersion & $2.42 \times 10^{-3}$ & $1.021 \times 10^{-9}$ & $1.491 \times 10^{9}$ & 0.9538 \\
\hline \multirow{2}{*}{ Cycle 4 times } & Before immersion & $8.07 \times 10^{-3}$ & $1.049 \times 10^{-9}$ & $3.102 \times 10^{9}$ & 0.9519 \\
& After immersion & $1.196 \times 10^{-2}$ & $1.07 \times 10^{-9}$ & $2.055 \times 10^{9}$ & 0.9506 \\
\hline \multirow{2}{*}{ Cycle 5 times } & Before immersion & $1.953 \times 10^{-4}$ & $1.073 \times 10^{-9}$ & $2.870 \times 10^{9}$ & 0.9512 \\
& After immersion & $4.17 \times 10^{-3}$ & $1.029 \times 10^{-9}$ & $2.015 \times 10^{9}$ & 0.9525 \\
\hline
\end{tabular}

Because the chemical components in the C-CE/TPU gel coating were aggregated by the hydrogen bond to form the gel coating and the hydrogen bond is reversible. The melting and spraying process will not change the microstructure of coating. Figure 14 is the FT-IR spectrum of C-CE/TPU after 10 times of melting. It shows that no functional group has changed during re-melting, which indicates that the chemical composition and chemical bonding are both stable during the cyclic melting. The boiling point of mineral oil is above $250{ }^{\circ} \mathrm{C}$ [45] and that of castor oil is above $330{ }^{\circ} \mathrm{C}$ [38]. There was no loss of oily components in the process of repeated heating and melting at $180^{\circ} \mathrm{C}$. At the same time, the water molecules, which have permeated into the coating, will evaporate to the air at the same temperature. It means the cyclic melting treatment has a healing effect on the gel coating. It is the reason why the decrease of coating weight and the recovery of coating resistance after each melt-spraying can been seen in Figure 12. From the above discussion, it could be concluded that the C-CE/TPU gel coating maintains good corrosion resistance and a stable mechanical property in cyclic tests because it has very good thermoplastic property, thermostability, and healing property due to the specific chemical composition and microstructure of this ethyl cellulose and TPU-based gel material. 

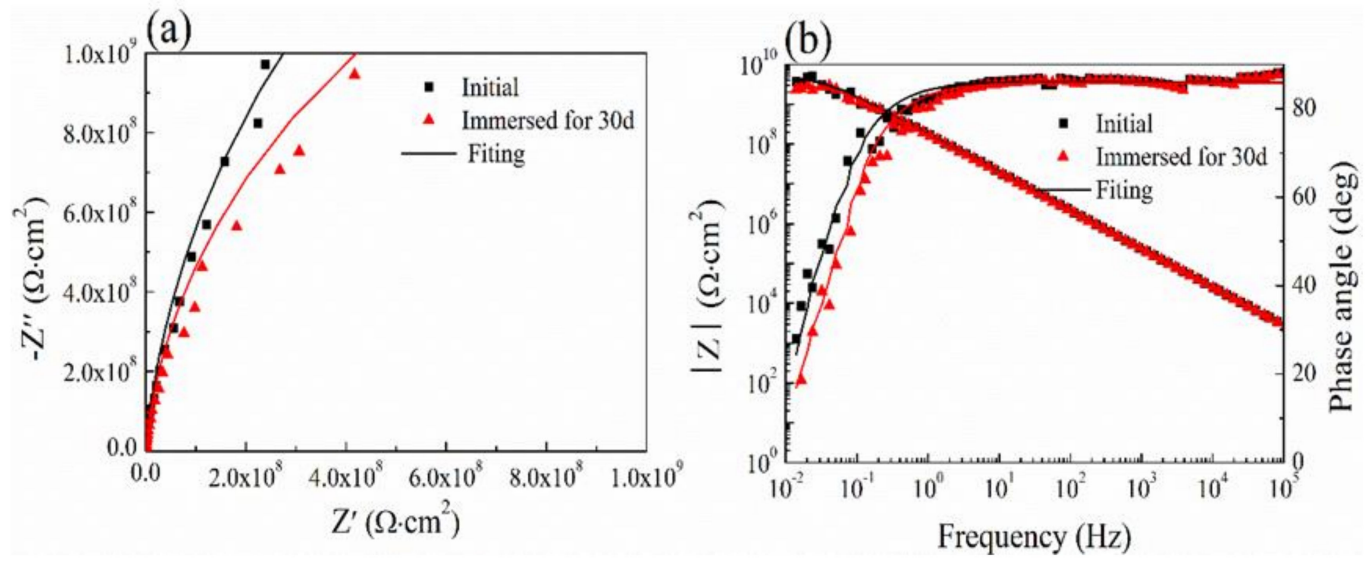

(c)

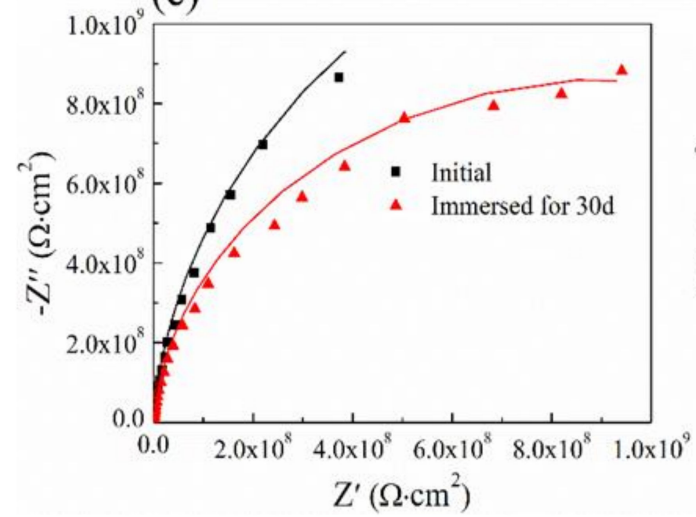

(d)

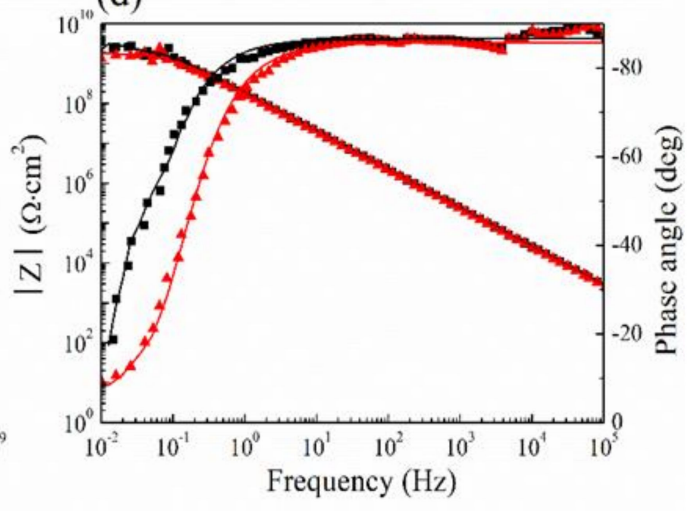

(e)
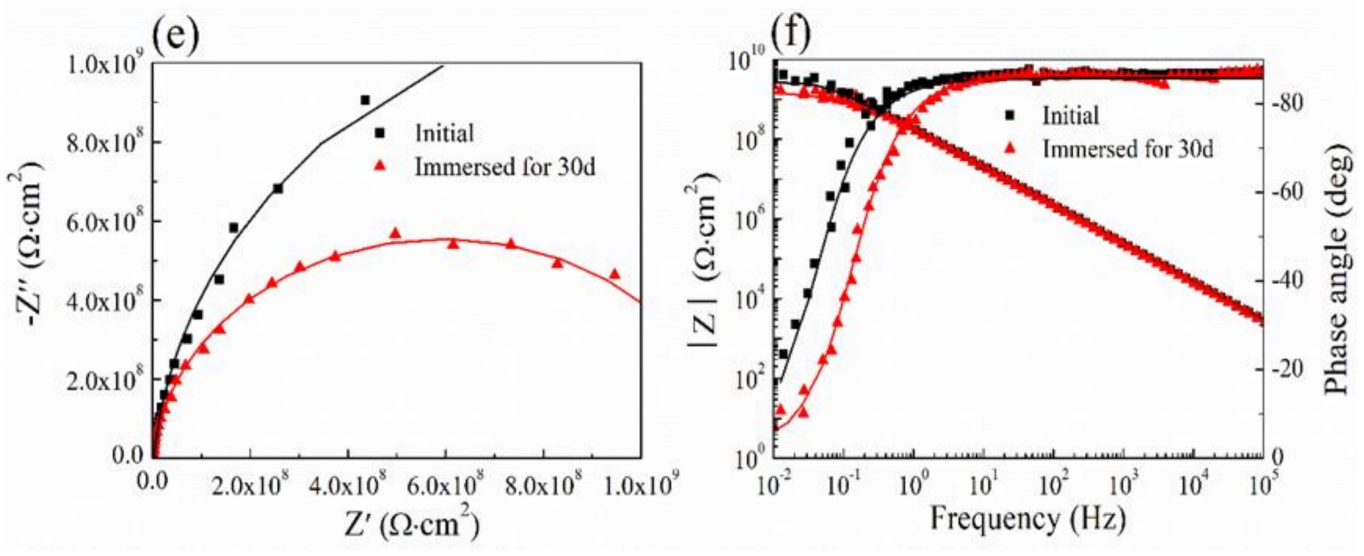

(g)
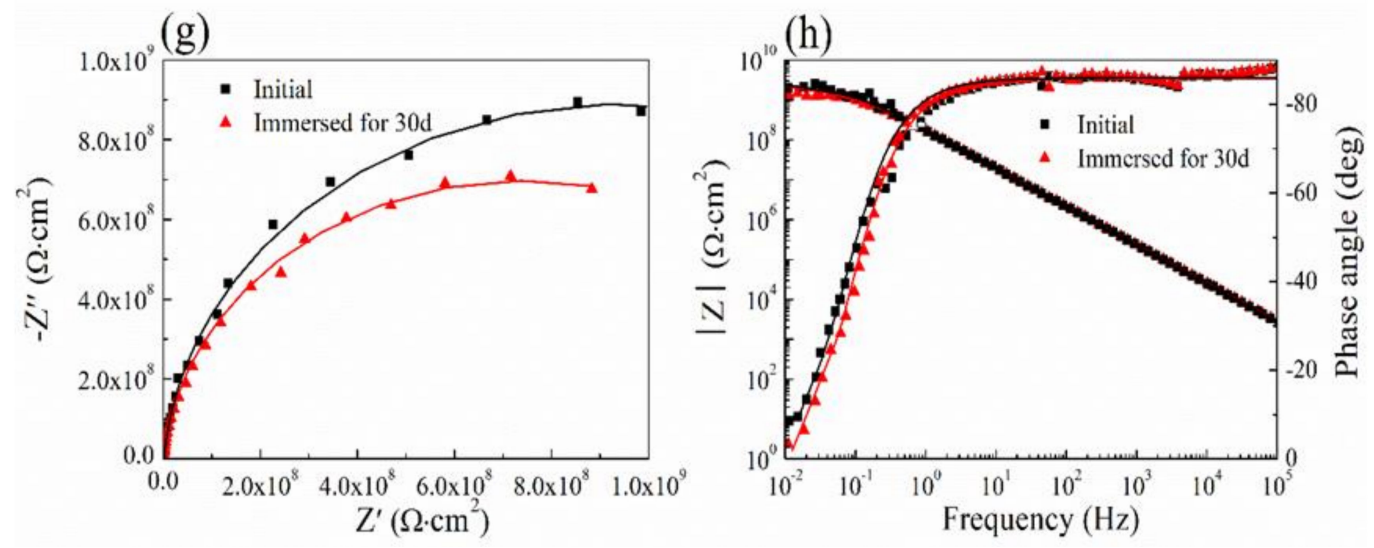

Figure 11. Cont. 

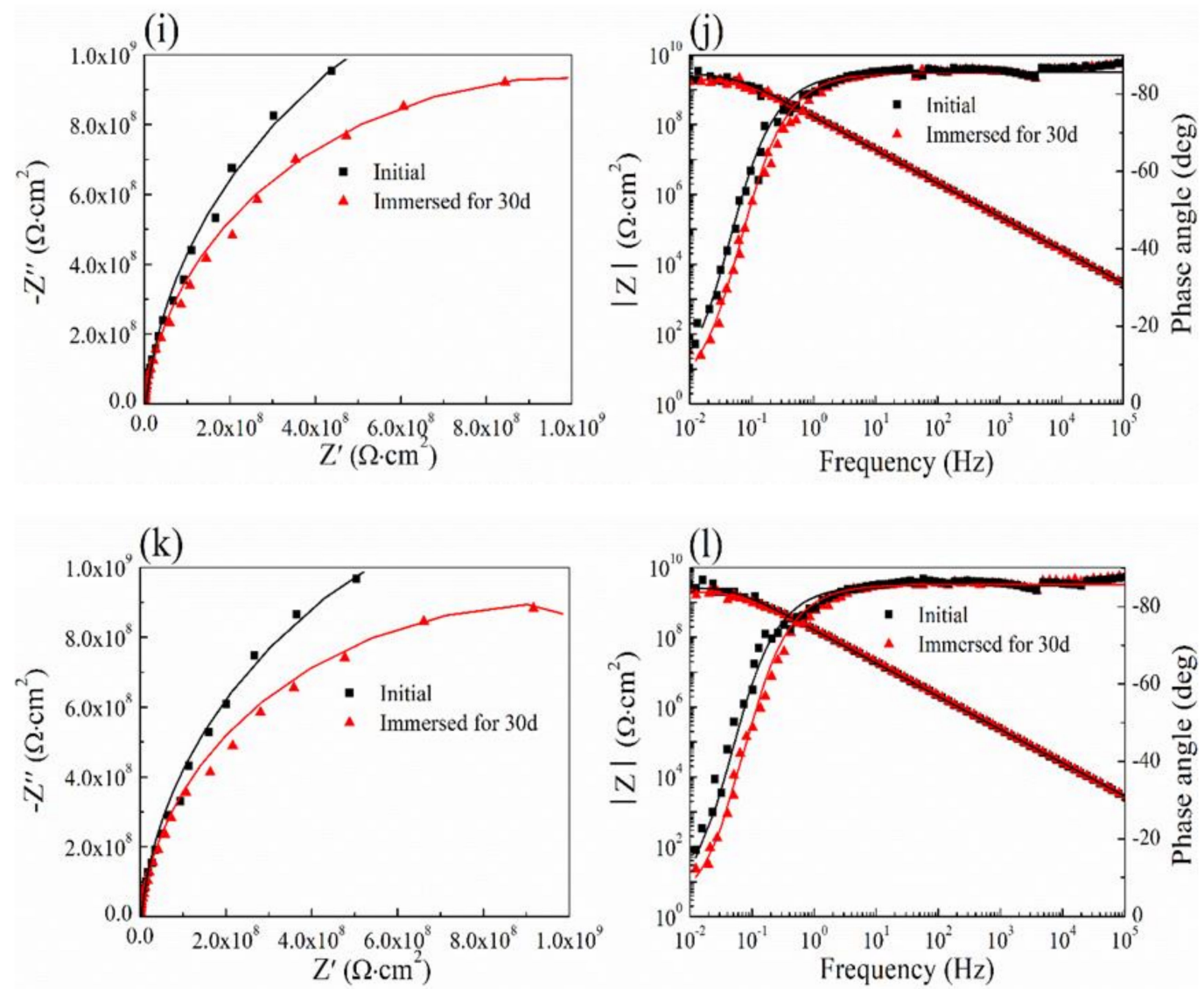

Figure 11. Electrochemical impedance spectra of C-EC/TPU coating for five cycles. The black square point stands for EIS of the initial state of coating while the red triangle point stands for the EIS after 30 days of immersion in $3.5 \mathrm{wt} . \% \mathrm{NaCl}$ solution. The line was the fitting results: $(\mathbf{a}, \mathbf{b})$ cycle 0 , (c,d) cycle 1, (e,f) cycle 2, (g,h) cycle $3,(\mathbf{i}, \mathbf{j})$ cycle $4,(\mathbf{k}, \mathbf{l})$ cycle 5.

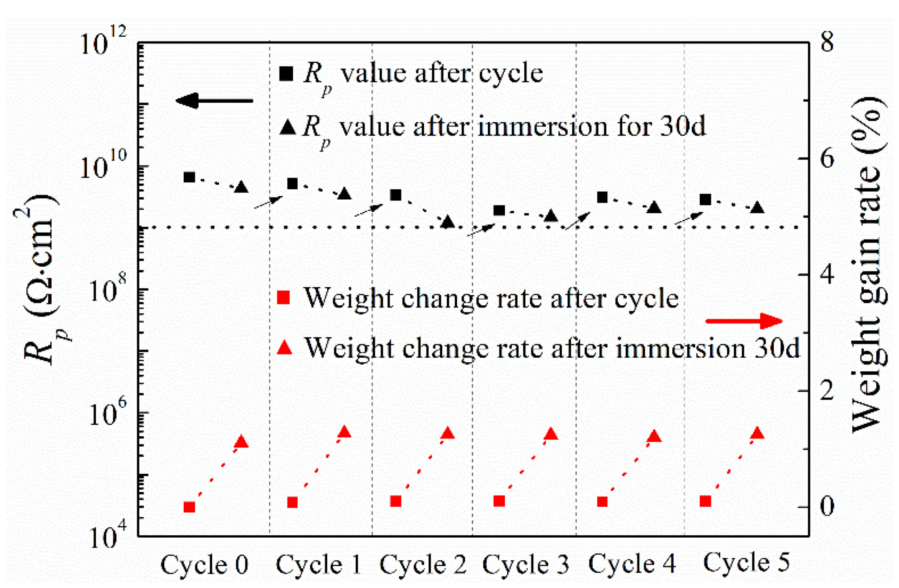

Figure 12. The change of the $R_{p}$ value and the weight change rate of the C-EC/TPU under different cycle test times. 


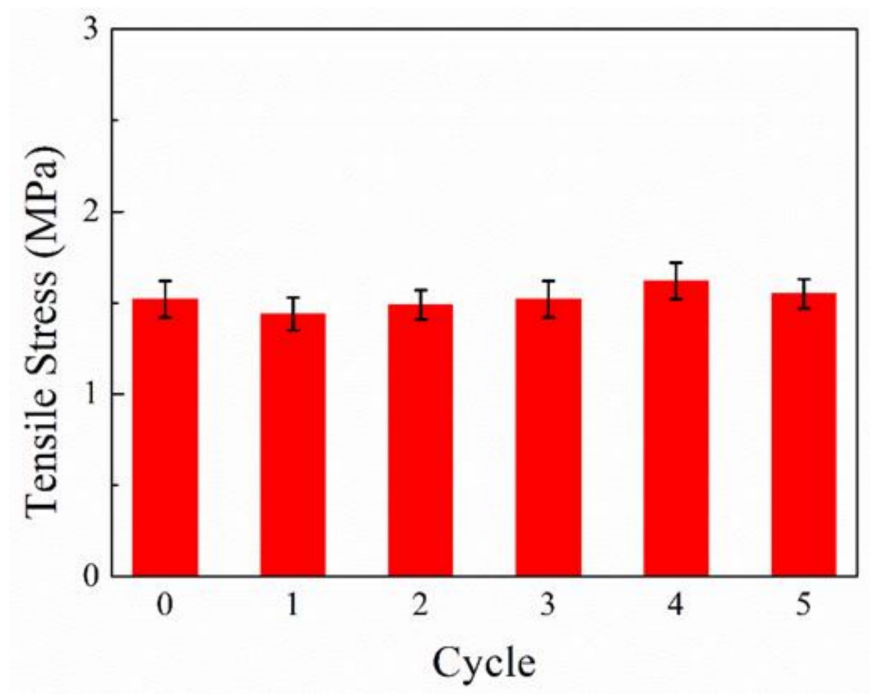

Figure 13. The tensile strength of the C-EC/TPU changes under different cycle test times.

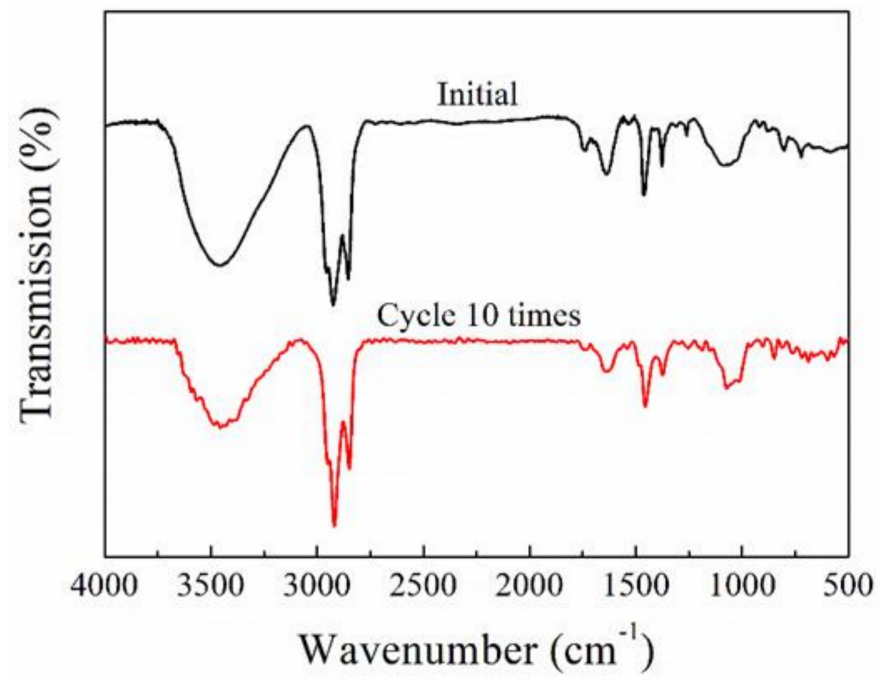

Figure 14. The FT-IR spectrum of the C-EC/TPU gel coating after 10 times of melting at $180{ }^{\circ} \mathrm{C}$.

\section{Conclusions}

In this paper, a recyclable anti-corrosive coating was prepared on carbon steel using the melt spray method from a novel organogel, which is synthesized by melt blending ethyl cellulose, thermoplastic elastomer, and oil together. The crosslinking structure was formed by the hydrogen bonding effect of EC, castor oil, and TPU molecules with each other, which formed a cage construction. Then the mineral oil was filled in the cage construction to form a thermoplastic gel. SEM and TEM observations show that the gel coating was dense and uniform in the microstructure, and it is composed of amorphous phase and crystalline phase as detected by XRD. The DMA measurement and tensile strength test revealed the TPU can also strengthen the mechanical property.

The neutral salt spray test, ultraviolet aging test, and EIS measurement show that the gel coating has good corrosion resistance. The cyclic performance of C-EC/TPU was further studied by EIS, weight measurement, infrared spectroscopy, and tensile strength test. After five cycles, the impedance value of the coating in EIS test was always higher than $10^{9} \Omega \cdot \mathrm{cm}^{2}$, and the weight change rate of the coating was always less than $1.5 \%$ after 30 days of immersion. The tensile strength of the coating material did not decrease. They are attributed to the good thermoplastic property and the good chemical stability 
of the gel coating. In addition, the healing property of the gel coating in the re-melting could improve the corrosion resistance in cyclic utilization.

The features of this novel coating are very different from the ordinary thermoplastic resin-based coating, that make it possible to be used for the corrosion protection of flange and valve connections in pipeline, and the bolting connections in different industries.

Author Contributions: Conceptualization, J.T. and H.W.; Data curation, H.Z. and S.Z.; Formal analysis, H.Z., J.T. and H.H.; Funding acquisition, H.Z., J.T., H.W. and Y.W.; Investigation, H.Z., S.Z. and Y.W.; Methodology, J.T., H.W., T.L. and B.L.; Project administration, H.Z.; Writing - original draft, H.H.; Writing - review \& editing, J.T.

Funding: This research was funded by Key R\&D Program of Science and Technology Department of Sichuan Province, China (Grant No. 18ZDYF3784 and 2018GZ0520), Foundation of Scientific Research Innovation Team of Universities Affiliated to Sichuan Province (Grant No. 18TD0012), and Applied Basic Research Programs of Science and Technology Department of Sichuan Province (Grant No. 2017JY0044).

Conflicts of Interest: The authors declare no conflict of interest.

\section{References}

1. King, A.D.; Kannan, B.; Scully, J.R. Environmental degradation of a Mg-rich primer in selected field and laboratory environments: Part 1-without a topcoat. Corrosion 2014, 70, 512-535. [CrossRef]

2. Wood, R.J.K. Marine wear and tribocorrosion. Wear 2017, 376-377, 893-910. [CrossRef]

3. Dong, S.; Zhao, B.; Lin, C.; Du, R.; Hu, R.; Zhang, G.X. Corrosion behavior of epoxy/zinc duplex coated rebar embedded in concrete in ocean environment. Constr. Build. Mater. 2012, 28, 72-78. [CrossRef]

4. Liu, B.; Fang, Z.G.; Wang, H.B.; Wang, T. Effect of cross linking degree and adhesion force on the anti-corrosion performance of epoxy coatings under simulated deep sea environment. Prog. Org. Coat. 2013, 76, 1814-1818. [CrossRef]

5. Fu, C.; Zhang, T.; Ji, C.; Cheng, F.; Cui, W.; Chen, Y. Optimizing heavy-duty anticorrosive performances of coating films formed by acrylate-vinylidene chloride copolymer latexes through twice-painting technique. Chin. J. Polym. Sci. 2015, 33, 14-22. [CrossRef]

6. Wang, N.; Gao, H.; Zhang, J.; Kang, P. Effect of graphene oxide/ZSM-5 hybrid on corrosion resistance of waterborne epoxy coating. Coatings 2018, 8, 179. [CrossRef]

7. Dastpak, A.; Yliniemi, K.; De Oliveira Monteiro, M.; Höhn, S.; Virtanen, S.; Lundström, M.; Wilson, B. From waste to valuable resource: Lignin as a sustainable anti-corrosion coating. Coatings 2018, 8, 454. [CrossRef]

8. Fu, C.; Qin, H.W.; Ben, H.J.; Han, J.; Cui, W.Z.; Cheng, F.; Chen, Y. Acrylate-vinylidene chloride copolymers derived from corresponding water-borne latexes: Influence of acrylate units on their potential as heavy-duty anticorrosive coating materials. J. Appl. Polym. Sci. 2014, 131, 1-9. [CrossRef]

9. Qi, Y.; Zhang, Z.; Wang, L.; Du, X. Investigation on anti-corrosion property of nano- $\mathrm{TiO}_{2}$ fluoro-carbon coatings. Proc. SPIE 2009, 7493, 74933D.

10. Fu, C.; Zhang, T.X.; Cheng, F.; Cui, W.Z.; Chen, Y. Double-layer coating films prepared from water-borne latexes of acrylate-vinylidene chloride copolymers: Investigating their heavy-duty anticorrosive properties. Ind. Eng. Chem. Res. 2014, 53, 4534-4543. [CrossRef]

11. Kismet, Y.; Wagner, M.H. Enhancing the potential of employing thermosetting powder recyclates as filler in LLDPE by structural modifications. J. Polym. Eng. 2017, 37, 287-296. [CrossRef]

12. Kismet, Y. Change of mechanical properties of powder recyclate reinforced polyolefin based on gamma radiation. Polymers 2017, 9, 384. [CrossRef] [PubMed]

13. Takeshita, Y.; Kamisho, T.; Sakata, S.; Sawada, T.; Watanuki, Y.; Nishio, R.; Ueda, T. Mixed powder coating film using thermoplastic polyester and its alkaline resistance. J. Coat. Technol. Res. 2013, 10, 503-514. [CrossRef]

14. Tohidi, S.D.; Rocha, A.M.; Dencheva, N.V.; Pouzada, A.S.; Denchev, Z. Comparative structural and mechanical studies on polyamide $6 \mathrm{knitted}$-reinforced single polymer composites prepared by different reactive processing techniques. Polym. Compos. 2019, 40, E886-E897. [CrossRef]

15. Takeshita, Y.; Kamisho, T.; Sakata, S.; Sawada, T.; Watanuki, Y.; Nishio, R.; Ueda, T. Dual layer structural thermoplastic polyester powder coating film and its weathering resistance. J. Appl. Polym. Sci. 2013, 128, 1732-1739. [CrossRef] 
16. Koning, C.E.; Sablong, R.J.; Hosseini Nejad, E.; Duchateau, R.; Buijsen, P. Novel coating resins based on polycarbonates and poly(ester-co-carbonate)s made by catalytic chain growth polymerization of epoxides with $\mathrm{CO}_{2}$ and with anhydride/CO 2 . Prog. Org. Coat. 2013, 76, 1704-1711. [CrossRef]

17. Gioia, C.; Vannini, M.; Celli, A.; Colonna, M.; Minesso, A. Chemical recycling of post-consumer compact discs towards novel polymers for powder coating applications. RSC Adv. 2016, 6, 31462-31469. [CrossRef]

18. Sauer, D.; Cerea, M.; Dinunzio, J.; McGinity, J. Dry powder coating of pharmaceuticals: A review. Int. J. Pharm. 2013, 457, 488-502. [CrossRef]

19. Adhikari, S.; Selvaraj, S.; Kim, D.H. Progress in powder coating technology using atomic layer deposition. Adv. Mater. Interfaces 2018, 5, 1-20. [CrossRef]

20. Yuan, W.; Yuan, J.; Zhang, F.; Xie, X. Syntheses, characterization, and in vitro degradation of ethyl cellulose-graft-poly( $\varepsilon$-caprolactone)-block-poly(L-lactide) copolymers by sequential ring-opening polymerization. Biomacromolecules 2007, 8, 1101-1108. [CrossRef]

21. Liu, Y.; Deng, L.; Zhang, C.; Chen, K.; Feng, F.; Zhang, H. Comparison of ethyl cellulose-gelatin composite films fabricated by electrospinning versus solvent casting. J. Appl. Polym. Sci. 2018, 135, 1-10. [CrossRef]

22. Masood, A.; Shoukat, Z.; Yousaf, Z.; Sana, M.; Faisal Iqbal, M.; Rehman, A.R.; Sultana, I.; Razaq, A. High capacity natural fiber coated conductive and electroactive composite papers electrode for energy storage applications. J. Appl. Polym. Sci. 2019, 136, 1-6. [CrossRef]

23. Gravelle, A.J.; Davidovich-Pinhas, M.; Zetzl, A.K.; Barbut, S.; Marangoni, A.G. Influence of solvent quality on the mechanical strength of ethylcellulose oleogels. Carbohydr. Polym. 2016, 135, 169-179. [CrossRef] [PubMed]

24. Maulvi, F.A.; Lakdawala, D.H.; Shaikh, A.A.; Desai, A.R.; Choksi, H.H.; Vaidya, R.J.; Ranch, K.M.; Koli, A.R.; Vyas, B.A.; Shah, D.O. In vitro and in vivo evaluation of novel implantation technology in hydrogel contact lenses for controlled drug delivery. J. Control. Release 2016, 226, 47-56. [CrossRef] [PubMed]

25. Yang, Y.; Wang, H.; Li, H.; Ou, Z.; Yang, G. 3D printed tablets with internal scaffold structure using ethyl cellulose to achieve sustained ibuprofen release. Eur. J. Pharm. Sci. 2018, 115, 11-18. [CrossRef] [PubMed]

26. Kempin, W.; Franz, C.; Koster, L.C.; Schneider, F.; Bogdahn, M.; Weitschies, W.; Seidlitz, A. Assessment of different polymers and drug loads for fused deposition modeling of drug loaded implants. Eur. J. Pharm. Biopharm. 2017, 115, 84-93. [CrossRef] [PubMed]

27. Yu, J.; Lu, C.; Wang, C.; Wang, J.; Fan, Y.; Chu, F. Sustainable thermoplastic elastomers derived from cellulose, fatty acid and furfural via ATRP and click chemistry. Carbohydr. Polym. 2017, 176, 83-90. [CrossRef] [PubMed]

28. Abbaspoor, S.; Ashrafi, A.; Abolfarsi, R. Development of self-healing coatings based on ethyl cellulose micro/nano-capsules. Surf. Eng. 2019, 35, 273-280. [CrossRef]

29. Pei, A.; Malho, J.M.; Ruokolainen, J.; Zhou, Q.; Berglund, L.A. Strong nanocomposite reinforcement effects in polyurethane elastomer with low volume fraction of cellulose nanocrystals. Macromolecules 2011, 44, 4422-4427. [CrossRef]

30. Mehta, B.; Kathalewar, M.; Sabnis, A. Benzyl ester of dehydrated castor oil fatty acid as plasticizer for poly(vinyl chloride). Polym. Int. 2014, 63, 1456-1464. [CrossRef]

31. El-Wahab, H.A.; El-Fattah, M.A.; Ghazy, M.B.M. Synthesis and characterization of new modified anti-corrosive polyesteramide resins incorporated pyromellitimide ring for surface coating. Prog. Org. Coat. 2011, 72, 353-359. [CrossRef]

32. Mishra, A.K.; Mishra, R.S.; Narayan, R.; Raju, K.V.S.N. Effect of nano ZnO on the phase mixing of polyurethane hybrid dispersions. Prog. Org. Coat. 2010, 67, 405-413. [CrossRef]

33. Mishra, S.K.; Pathak, K. Formulation and evaluation of oil entrapped gastroretentive floating gel beads of loratadine. Acta Pharm. 2008, 58, 187-197. [CrossRef]

34. Yang, Z.; Peng, H.; Wang, W.; Liu, T. Crystallization behavior of poly( $\varepsilon$-caprolactone)/layered double hydroxide nanocomposites. J. Appl. Polym. Sci. 2010, 116, 2658-2667. [CrossRef]

35. Abd-Elrahman, M.I.; Ahmed, M.O.; Abdel-Aleem, J.A. Optical properties of cellulose derivatives blend film carrying a chalcogenide material. Mater. Sci. Semicond. Process. 2013, 16, 1052-1056. [CrossRef]

36. Selim, M.S.; El-safty, S.A.; El-sockary, M.A.; Hashem, A.I.; Abo, O.M.; El-saeed, A.M.; Fatthallah, N.A. Smart photo-induced silicone/ $\mathrm{TiO}_{2}$ nanocomposites with dominant [110] exposed surfaces for self-cleaning foul-release coatings of ship hulls. JMADE 2016, 101, 218-225. 
37. Mohanan, A.; Bouzidi, L.; Narine, S.S. Mitigating crystallization of saturated FAMEs in biodiesel 6: The binary phase behavior of 1, 2-dioleoyl-3-stearoyl sn-glycerol-Methyl stearate. Energy 2016, 100, $273-284$. [CrossRef]

38. Ogunniyi, D.S. Castor oil: A vital industrial raw material. Bioresour. Technol. 2006, 97, 1086-1091. [CrossRef]

39. Huda, M.S.; Drzal, L.T.; Mohanty, A.K.; Misra, M. Effect of fiber surface-treatments on the properties of laminated biocomposites from poly(lactic acid) (PLA) and kenaf fibers. Compos. Sci. Technol. 2008, 68, 424-432. [CrossRef]

40. Alemdar, A.; Sain, M. Biocomposites from wheat straw nanofibers: Morphology, thermal and mechanical properties. Compos. Sci. Technol. 2008, 68, 557-565. [CrossRef]

41. Das, S.; Pandey, P.; Mohanty, S.; Nayak, S.K. Investigation into the Influence of UV Aging on green polyurethane/nanosilica composite coatings based on transesterified castor oil and palm oil isocyanate. J. Inorg. Organomet. Polym. Mater. 2017, 27, 641-657. [CrossRef]

42. Zhang, H.; Dun, Y.; Tang, Y.; Zuo, Y.; Zhao, X. Correlation between natural exposure and artificial ageing test for typical marine coating systems. J. Appl. Polym. Sci. 2016, 43893, 1-9. [CrossRef]

43. Liu, J.; Liu, T.; Guo, Z.; Guo, N.; Lei, Y.; Chang, X.; Yin, Y. Promoting barrier performance and cathodic protection of zinc-rich epoxy primer via single-layer graphene. Polymers 2018, 10, 591. [CrossRef]

44. Nawaz, M.; Yusuf, N.; Habib, S.; Shakoor, R.A.; Ubaid, F.; Ahmad, Z.; Kahraman, R.; Mansour, S.; Gao, W. Development and properties of polymeric nanocomposite coatings. Polymers 2019, 11, 852. [CrossRef]

45. Wang, X.F.; Wang, Z.D.; Liu, Q.; Dyer, P. Dissolved gas analysis of thermal faults in transformer liquids simulated using immersed heating method. IEEE Trans. Dielectr. Electr. Insul. 2018, 25, 1749-1757. [CrossRef]

(C) 2019 by the authors. Licensee MDPI, Basel, Switzerland. This article is an open access article distributed under the terms and conditions of the Creative Commons Attribution (CC BY) license (http://creativecommons.org/licenses/by/4.0/). 